\title{
Reactivation of the quiescent corpus luteum and diapausing embryo after temporary removal of the sucking stimulus in the tammar wallaby (Macropus eugenii)
}

\author{
K. Gordon*, T. P. Fletcher and M. B. Renfree \\ Department of Anatomy, Monash University, Melbourne, Victoria 3168, Australia
}

\begin{abstract}
Summary. Pouch young of wallabies presumed to be carrying diapausing blastocysts were removed from the teat for times varying between 24 and $96 \mathrm{~h}$ and then returned to the same teat. The mothers were monitored for termination of diapause and checked for births or oestrus. In this way we were able to determine the critical time required to reactivate the quiescent corpus luteum and diapausing blastocyst after withdrawal of the sucking stimulus. When pouch young were removed from the teat for $76-96 \mathrm{~h}$ the corpus luteum and blastocyst were reactivated, with birth and/or oestrus occurring in $10 / 11$ animals. When pouch young were removed for $72 \mathrm{~h}$ or less $(n=22)$ reactivation did not take place.

We conclude that it takes longer than $72 \mathrm{~h}$ for the maternal endocrine system to become committed to reactivation. The precise sequence of endocrine events which precede blastocyst reactivation still remains to be determined.
\end{abstract}

Keywords: corpus luteum; sucking; tammar; diapause; blastocyst

\section{Introduction}

Female tammar wallabies, Macropus eugenii, like most macropodid marsupials, usually mate and conceive again less than $24 \mathrm{~h}$ post partum. The newly formed embryo develops for approximately 8 days, reaching an 80-100-cell blastocyst, but further development is inhibited if the newborn young has attached to one of the four teats in the pouch (Berger, 1966; Tyndale-Biscoe \& Renfree, 1987). During the breeding season (February-May), accidental loss or removal of the pouch young leads to the reactivation of the quiescent blastocyst and subsequent birth in $75-87 \%$ of animals, while $13-21 \%$ fail to conceive at the previous post-partum oestrus and undergo an infertile cycle with a subsequent mating (Renfree \& Tyndale-Biscoe, 1973). Birth occurs 26-27 days after removal of pouch young and oestrus 1 day after that (Merchant, 1979; Tyndale-Biscoe \& Renfree, 1987).

The proximate signal for this inhibition of blastocyst development comes from the small pouch young sucking on the teat, since denervation of the sucked mammary glands results in blastocyst reactivation (Renfree, 1979). How the sucking stimulus inhibits blastocyst development is not fully understood, but it is assumed that the neural stimuli are acting via the hypothalamo-pituitary axis and ultimately to influence the corpus luteum and hence the blastocyst. The pituitary inhibition of blastocyst reactivation during lactation (Hearn, 1974) appears to be mediated by prolactin (Tyndale-Biscoe \& Hawkins, 1977).

There is a critical period after Day 2 after removal of pouch young and before Day 4 when ovariectomy or excision of the corpus luteum is followed by a resumption of blastocyst growth and

\footnotetext{
*Present address: Division of Pregnancy Research, The Howard \& Georgeanna Jones Institute for Reproductive Medicine, Eastern Virginia Medical School, Lewis Hall, Norfolk, Virginia 23507, U.S.A.
} 
subsequent collapse and by failure of the endometrium to become secretory (Sharman \& Berger, 1969): ovariectomy or luteal excision before this stage blocks reactivation, and after this stage allows fetal development to full term (Tyndale-Biscoe, 1970; Young \& Renfree, 1979). When reactivation is stimulated by exogenous progesterone, which by-passes the corpus luteum, the fetus takes 3 days less to reach full term than after removal of pouch young, so it has been assumed that the corpus luteum takes 3 days to reactivate after sucking stimulus withdrawal (Renfree \& Tyndale-Biscoe, 1973; Tyndale-Biscoe, 1979).

The first measurable signs of blastocyst reactivation are an increased uterine metabolism and an increased RNA metabolism of the blastocyst on Days 4 and 5 after removal of pouch young, respectively (Moore, 1978; Thornber et al., 1981; Shaw \& Renfree, 1986). During spontaneous reactivation the increased uterine metabolic activity (Shaw \& Renfree, 1986) occurs before a transient rise in peripheral progesterone concentration at around Day 5 after removal of pouch young (Hinds \& Tyndale-Biscoe, 1982; Shaw \& Renfree, 1984). However, the time course of the changes between withdrawal of the sucking stimulus and the first signs of reactivation by the corpus luteum and uterus has not yet been defined. This paper aims to clarify the first of these points, that is the precise time for which the sucking stimulus must be withdrawn to reactivate the corpus luteum and, if present, the diapausing blastocyst.

\section{Materials and Methods}

All tammars were from a breeding colony maintained in outdoor enclosures at Monash University, Melbourne, Victoria, Australia. Forty-five adult females expected to have diapausing blastocysts which were also carrying similar aged pouch young (20-60 days, Groups 1-4; or 20-40 days, Groups 5-9) were randomly assigned to 9 experimental groups of 5 animals. Each group was housed in separate small outdoor enclosures for the duration of the experiment and maintained as previously described (Renfree \& Tyndale-Biscoe, 1978).

Experimental design. The experiment was performed in two trials, Groups 1-4 in April 1985 and Groups 5-9 in February 1986. The experimental design with the number of treatment groups, the duration of pouch young removal per treatment, time of expected birth after initial pouch young removal and the period of 4-h blood sampling is shown in Fig. 1. The day of pouch young removal was designated as Day 0 . At 08:00 $\mathrm{h}$ pouch young were removed from all animals (first removal). Age-matched pouch young were reattached to the teat after $24 \mathrm{~h}$ (Group 1), $36 \mathrm{~h}$ (Group 2), $48 \mathrm{~h}$ (Group 3), $56 \mathrm{~h}$ (Group 4), $64 \mathrm{~h}$ (Group 5), $72 \mathrm{~h}$ (Group 6), $84 \mathrm{~h}$ (Group 7) and $96 \mathrm{~h}$ (Group 8). Pouch young of Group 9 (control) animals were not replaced. Adults were checked daily from Day 25 after first removal of pouch young for the presence of newborn young and/or mating plugs which indicate oestrus. Adult males were run with all groups from Day 18 to facilitate the detection of oestrus and to ensure pregnancy as part of our normal colony husbandry procedure. Reattached pouch young from all of Groups 5-8 were removed (second removal of pouch young) 25 days after the first removal of pouch young (or 2 days before any births could have occurred) to ensure that new pouch young would have a vacant pouch to enter.

Pouch young reattachment. Mothers were gently restrained in a hessian sack, the pouch opened and the pouch young replaced by a second person gently pushing the lactating teat into the mouth of the young with the end of a matchstick. The pouch young was eased back into the pouch and the pouch allowed to close. The mother was then encouraged to stand up (within the sack). The wallabies were checked after 15-30 min and any pouch young that were found to be detached were replaced as described, and the mother immediately released. All animals were examined at 4- $\mathrm{h}$ intervals for $12 \mathrm{~h}$ and thereafter daily until Day 7, and then on Days 14, 16, 22 and 25. Animals were again checked daily between Days 25 and 58, or until they gave birth or mated, whichever was sooner. Any unattached young were replaced as described up to Day 3 , thereafter they were left unattached.

Blood sampling. Blood samples $(5 \mathrm{ml})$ were taken daily from all animals for 2 days before the day of pouch young removal. On Day 0, blood samples were taken $4 \mathrm{~h}$ and immediately before removal of pouch young, then at 4-h intervals until $12 \mathrm{~h}$ after removal of pouch young. Blood samples were then taken every $8 \mathrm{~h}$ until $8 \mathrm{~h}$ before pouch young replacement when 4-h sampling was resumed which continued for $12 \mathrm{~h}$ after replacement of pouch young. Animals in the control group (Group 9) were sampled following the same regimen as the $56 \mathrm{~h}$ (or median) group (Group 4). Samples were then taken daily until Day 7 and on Days 14, 16, 22 and 25.

Hormone assay. Prolactin was measured by the heterologous double-antibody radioimmunoassay described by Tyndale-Biscoe \& Hinds (1984). The antiserum 33/1-8 was raised in guinea-pigs against human prolactin. The standard and radioligand was NIADDK-oPrl-Il (AFP 4328C). The assay sensitivity was $0.28 \mathrm{ng} / \mathrm{ml}$ and interassay coefficients of variation were $8.5,16 \cdot 6$ and $19.5 \%$ for 3 plasma pools containing $21.4,1.4$ and $0.74 \mathrm{ng}$ prolactin $/ \mathrm{ml}$ respectively and intra-assay coefficient of variation was $6.5 \%(n=12)$. All samples from individual animals were measured in the same assay. 


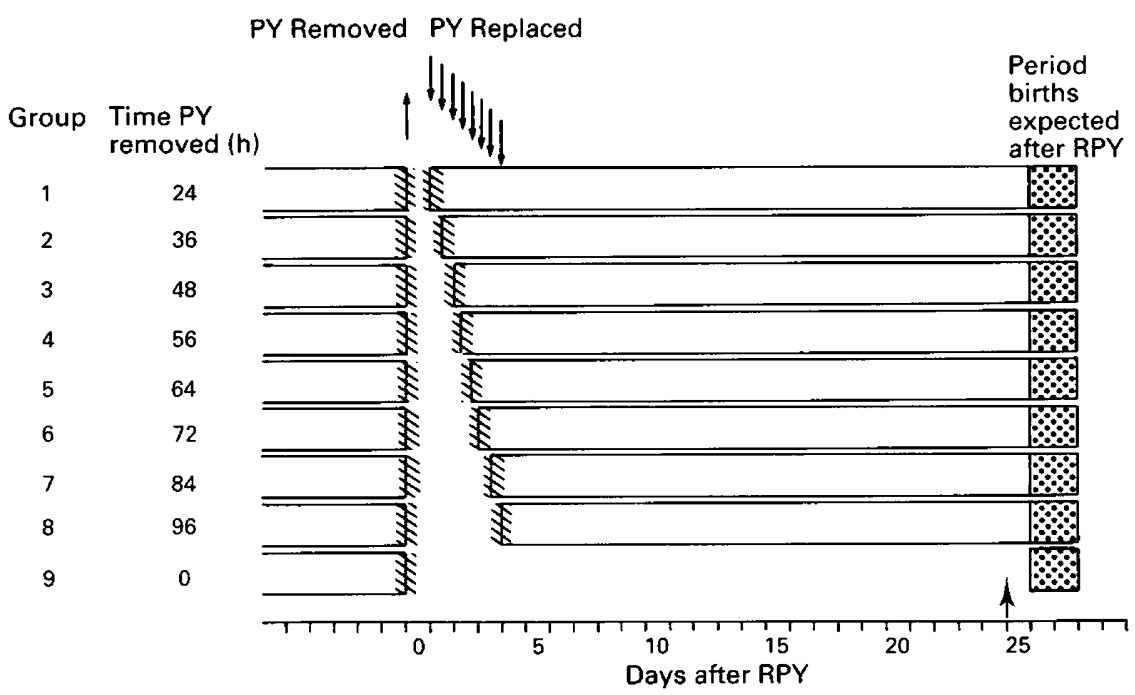

Fig. 1. Diagrammatic representation of the experimental design, showing the number of treatments (Groups 1-9) and the duration of withdrawal of the sucking stimulus (h). The open horizontal bars indicate presence of a pouch young (PY) on the teat and the diagonally hatched areas indicate the times of two periods of 4-h blood sampling for each group. The time of first removal of pouch young (RPY) and the replacement times for each group are indicated by arrows at the appropriate times. Additional single blood samples were taken at Days 14, 16, 22 and 25 after first removal of pouch young. The time that births were expected after the first removal of pouch young is shown by the stippled areas $i$. In Groups 5,6,7 and 8, successfully reattached pouch young were removed (second removal of pouch young, spearhead), at Day 25 after first removal of pouch young to provide a vacant pouch for any new births 2 days later.

Time of reactivation. Reactivation of the quiescent $\mathrm{CL}$ and, if present, the diapausing blastocyst was confirmed by a birth and/or mating 27-30 days after removal of pouch young. If reactivation occurred in response to the second removal of pouch young, birth and oestrus would all occur at the appropriate times relative to the second, but not the first, removal of pouch young.

\section{Results}

\section{Reactivation after removal and replacement of the pouch young}

The number of pouch young reattached to the mother's teat (33/40) and the number of wallabies with reattached pouch young that reactivated after first removal of pouch young for each group $(0 / 22$ removed for up to $72 \mathrm{~h} ; 10 / 11$ removed from $76-96 \mathrm{~h} ; 4 / 5$ never replaced) are shown in Table 1.

Groups $1-4$. Of 20 pouch young, 5 did not reattach to the teat. Of these 5 females, 4 had a pregnant cycle; the 5 th had a non-pregnant cycle but did mate. In Groups $1-4,15 / 20$ pouch young successfully reattached: 9 pouch young were lost between the end of daily checking (Day 7) and Day 14 when animals were once again checked (effectively, second removal of pouch young). All subsequently gave birth or mated, but since the time of subsequent birth or mating was known, the estimated day of reactivation was found to correspond to the period when the animals were not checked (specifically for each animal this was Days 7, 8, 9, 9, 10, 10,11,13 and 14 after first removal of pouch young), at least 1 week or more after the time of first removal of pouch young. Of the 6 remaining animals which had reattached young that stayed attached, 4 produced neonatal young at the start of the next breeding season, confirming they had been pregnant at the time of the 
Table 1. The number of animals in each experimental group with a reactivated* corpus luteum after temporary removal of their pouch young (first removal of PY) for the time (h) shown

\begin{tabular}{cccc}
\hline Group & $\begin{array}{c}\text { Period } \\
\text { PYmoved } \\
\text { (h) } \dagger\end{array}$ & $\begin{array}{c}\text { No. of PY } \\
\text { reattached }\end{array}$ & $\begin{array}{c}\text { No. of wallabies with } \\
\text { reattached PY that } \\
\text { reactivated after first RPY }\end{array}$ \\
\hline 1 & $24(32)$ & $3 / 5$ & $0 / 3$ \\
2 & 36 & $4 / 5$ & $0 / 4$ \\
3 & $48(52)$ & $4 / 5$ & $0 / 4$ \\
4 & 56 & $4 / 5$ & $0 / 4$ \\
5 & 64 & $5 / 5$ & $0 / 5$ \\
6 & 72 & $2 / 2$ & $0 / 2$ \\
& 76 & $2 / 3$ & $2 / 2$ \\
7 & 84 & $4 / 5$ & $3 / 4$ \\
8 & 96 & $5 / 5$ & $5 / 5$ \\
9 & - & 0 & -4 \\
\hline
\end{tabular}

*Reactivation was assessed by birth or mating.

$\dagger$ Times shown in parentheses are the actual times that pouch young reattached for Groups 1 and 3: 7 pouch young never successfully reattached. Group 9 (control group) pouch young, once removed, were not reattached.

$\$ 4 / 5$ gave birth Day $26-27$ after removal of pouch young.

experiment. Therefore, birth and/or mating did not occur as a result of the first removal of pouch young for up to $56 \mathrm{~h}$.

Groups 5-9. Eighteen of 20 pouch young successfully reattached in Groups 5-8. In Group 5 all the pouch young were successfully reattached and reactivation did not occur until after 27 days after the second removal of pouch young, when 3 gave birth, and 2 had mating plugs only. Of the pouch young replaced after $72 \mathrm{~h}$ (Group 6), $2 / 5$ reattached to the teat at the first attempt and the mother did not reactivate. Two of the remaining 3 animals reattached at the next attempt $(76 \mathrm{~h})$ and each of these females reactivated their diapausing embryo. Withdrawal of the sucking stimulus for $84 \mathrm{~h}$ or greater (Groups 7-9) resulted in reactivation in 12/14 of animals even though the young were successfully reattached in Groups 7 and 8 . Of the females with pouch young attached for $76-$ $96 \mathrm{~h}, 10 / 11$ either gave birth or mated 27-30 days after the first removal of pouch young. Their reproductive system had therefore been released from the inhibitory effects of the sucking stimulus. This was not affected by continuation of the sucking stimulus after replacement of the pouch young $76 \mathrm{~h}$ or longer or by removal of the replaced young (second removal of pouch young) 25 days after first removal of pouch young. Thus, overall, of 45 animals, 37 animals were pregnant, mating alone was recorded in 5 , and 3 had neither a mating nor a birth. These proportions are in accord with those of Renfree \& Tyndale-Biscoe (1973).

\section{Plasma prolactin concentrations}

We could not detect a marked or sustained response to removal of pouch young or pouch young replacement reflected in peripheral plasma prolactin concentrations. The mean concentrations ( \pm s.e.m.) of plasma prolactin measured for Groups $1-4$ ranged from $1.5 \pm 0.07 \mathrm{ng} / \mathrm{ml}$ to $1.88 \pm 0.14 \mathrm{ng} / \mathrm{ml}$ before removal of pouch young. In all groups there were small but variable changes of between 0.25 and $0.5 \mathrm{ng} / \mathrm{ml}$ in the prolactin concentrations in the samples taken $4 \mathrm{~h}$ after removal of pouch young and after pouch young replacement. In Groups 5-9 in many cases the plasma concentrations were around the limit of the assay sensitivity and, with an inter-assay variation of $16 \cdot 6-19.5 \%$ for the range of concentrations measured, it is impossible to draw any conclusions from these results. 


\section{Discussion}

This study demonstrates that the sucking stimulus must be absent for more than $72 \mathrm{~h}$, but less than $76 \mathrm{~h}$, after removal of the pouch young to allow the corpus luteum to escape from inhibition and initiate development of dormant blastocysts. This is only 1 day before the earliest changes can be measured in the uterine metabolism (Shaw \& Renfree, 1986) and 2 days before the earliest change can be detected in the blastocyst (Moore, 1978; Thornber et al., 1981; Shaw \& Renfree, 1986) or in the transient rises in the peripheral plasma concentrations of progesterone (Hinds \& Tyndale-Biscoe, 1982) and oestradiol (Shaw \& Renfree, 1984).

Whilst the possibility that the presence of an unattached pouch young may in some way influence the maternal endocrine system cannot be completely discounted, reactivation occurred in the Group 6 animals in which the pouch young became detached but present in the pouch for an additional $4 \mathrm{~h}$, confirming that it is the sucking stimulus itself which is important. This is in accord with the observations of Renfree (1979) that denervation of the sucked teat resulted in reactivation while the pouch young was still present.

The process of removing and then replacing pouch young is likely to have caused the animals some stress, which might be expected to delay the reactivation. This was apparently not the case as the animals in Groups 6-8 with pouch young replaced repeatedly or unsuccessfully gave birth at the normal time, 27-29 days after removal of pouch young. Furthermore, the frequent blood sampling associated with this experiment did not influence the time of birth in the control animals (Group 9). Stresses associated with handling or venepuncture did not cause any measurable change in prolactin concentration in Group 9 around the time of frequent blood sampling when replacement would have taken place. Likewise, the removal or replacement of pouch young did not cause a marked change in prolactin concentrations. Hinds \& Tyndale-Biscoe (1982) also failed to detect any changes in prolactin concentrations after removal of pouch young in early lactation (Days $0-120$ ) when concentrations are low, although there was a marked decrease after removal of pouch young in late lactation and an increase when the young were replaced (Days 203-242) (Hinds \& Tyndale-Biscoe, 1985). Similarly, during the breeding season when prolactin concentrations are low a single injection of bromocriptine can initiate blastocyst reactivation, but there is no change in the prolactin concentration measured in once daily samples (Tyndale-Biscoe \& Hinds, 1984).

Since the sucking stimulus must be removed for at least 3 days for reactivation to occur, and the timing of births in response to both removal of pouch young and bromocriptine treatment are the same, it would appear that the influence of bromocriptine lasts more than $72 \mathrm{~h}$. In rhesus monkeys, a single injection of $30 \mathrm{mg}$ bromocriptine can suppress prolactin for at least 6 days (Schallenberger et al., 1981). However, Tyndale-Biscoe et al. (1986) suggest that the basal levels of prolactin may be unimportant, and that the inhibition of the corpus luteum may result from one or more transient pulses of prolactin which they observed at 'lights on'. There is some evidence that pulses of prolactin, which are loosely associated with dawn and/or dusk, depending on the time of year, occur in some lactating (Hinds \& Tyndale-Biscoe, 1985) and in non-lactating animals (Gordon, 1986; K. Gordon, T. P. Fletcher, R. V. Short \& M. B. Renfree, unpublished results). If these pulses are indeed crucial signals for the inhibition of reactivation, it is possible that removal of pouch young at a different time of the day, e.g. $20: 00 \mathrm{~h}$, could give up to $12 \mathrm{~h}$ variation in the required time for withdrawal of the sucking stimulus.

The results of this experiment clearly demonstrate that the sucking stimulus must be removed for at least $72 \mathrm{~h}$ for reactivation of the corpus luteum and blastocyst to become inevitable.

We thank D. Blanden, Dr P. Lewis, N. Robinson, Dr G. Shaw and Professor R. V. Short for assistance in animal handling and collection of blood samples; and Dr G. Shaw and Professor R. V. Short for helpful criticisms of the manuscript. The study was supported by a National Health \& Medical Research Council project grant to Dr M. B. Renfree and Professor R. V. Short. The 
animals were held under permit No. 84-28, Department of Conservation, Forests and Lands, Melbourne, Victoria, Australia. The prolactin antiserum was provided by Dr A. S. McNeilly (Edinburgh, U.K.) and the prolactin standard by the National Hormone Pituitary Program (University of Maryland, U.S.A.).

\section{References}

Berger, P.J. (1966) Eleven-month 'embryonic diapause' in a marsupial. Nature, Lond. 211, 435-436.

Gordon, K. (1986) The role of $\beta$-endorphin in the lactational inhibition of reproduction in the sheep and tammar wallaby. Ph.D. thesis, Monash University.

Hearn, J.P. (1974) The pituitary gland and implantation in the tammar wallaby, Macropus eugenii. J. Reprod. Fert. 39, 235-241.

Hinds, L.A. \& Tyndale-Biscoe, C.H. (1982) Plasma progesterone levels in the pregnant and non-pregnant tammar, Macropus eugenii. J. Endocr. 93, 99-107.

Hinds, L.A. \& Tyndale-Biscoe, C.H. (1985) Seasonal and circadian patterns of circulating prolactin during lactation and seasonal quiescence in the tammar, Macropus eugenii. J. Reprod. Fert. 74, 173-183.

Merchant, J.C. (1979) The effect of pregnancy on the interval between one oestrus and the next in the tammar wallaby, Macropus eugenii. J. Reprod. Fert. 56, 459463.

Moore, G.P.M. (1978) Embryonic diapause in the marsupial Macropus eugenii. Stimulation of nuclear RNA polymerase activity in the blastocyst during resumption of development. J. Cell. Physiol. 94, $31-36$.

Renfree, M.B. (1979) Initiation of development of diapausing embryo by mammary denervation during lactation in a marsupial. Nature, Lond. 278, 549-551.

Renfree, M.B. \& Tyndale-Biscoe, C.H. (1973) Intrauterine development after diapause in the marsupial, Macropus eugenii. Devl Biol. 32, $28-40$.

Renfree, M.B. \& Tyndale-Biscoe, C.H. (1978) Manipulation of marsupial embryos and pouch young. In Methods of Mammalian Reproduction, pp. 307-331. Ed. J.C. Daniel. Academic Press, New York.

Schallenberger, E., Richardson, D.W. \& Knobil, E. (1981) Role of prolactin in the lactational amenorrhea of the rhesus monkey (Macaca mulatta). Biol. Reprod. 25, $370-374$

Sharman, G.B. \& Berger, P.J. (1969) Embryonic diapause in marsupials. Adv. Reprod. Physiol. 4, $211-240$.
Shaw, G. \& Renfree, M.B. (1984) Concentrations of oestradiol-17 $\beta$ in plasma and corpora lutea throughout pregnancy in the tammar, Macropus eugenii. $J$. Reprod. Fert. 72, 29-37.

Shaw, G. \& Renfree, M.B. (1986) Uterine and embryonic metabolism after diapause in the tammar wallaby, Macropus eugenii. J. Reprod. Fert. 76, 339-347.

Thornber, E.J., Renfree, M.B. \& Wallace, G.J. (1981) Biochemical studies of intrauterine components of the tammar wallaby, Macropus eugenii during pregnancy. J. Embryol. Exp. Morph. 62, 325-338.

Tyndale-Biscoe, C.H. (1970) Resumption of development by quiescent blastocysts transferred to primed, ovariectomized recipients in the marsupial, Macropus eugenii. J. Reprod. Fert. 23, 25-32.

Tyndale-Biscoe, C.H. (1979) Hormonal control of embryonic diapause and reactivation in the tammar wallaby. In Maternal Recognition of Pregnancy (Ciba Foundation Symposium (new series)), pp. 173-90. Excerpta Medica, Amsterdam.

Tyndale-Biscoe, C.H. \& Hawkins, J. (1977) The corpora lutea of marsupials: Aspects of function and control. In Reproduction and Evolution, pp. 245-252. Eds J. H. Calaby \& C. H. Tyndale-Biscoe. Australian Academy of Science, Canberra.

Tyndale-Biscoe, C.H. \& Hinds, L.A. (1984) Seasonal patterns of circulating progesterone and prolactin and response to bromocriptine in the female tammar, Macropus eugenii. Gen. comp. Endocr. 53, 58-68.

Tyndale-Biscoe, C.H. \& Renfree, M.B. (1987) Reproductive Physiology of Marsupials. Cambridge University Press, 476 pp.

Tyndale-Biscoe, C.H., Hinds, L.A. \& McConnell, S.J. (1986) Seasonal breeding in a marsupial: opportunities of a new species for an old problem. Recent Prog. Horm. Res. 42, 471-512.

Young, I.R. \& Renfree, M.B. (1979) The effects of corpus luteum removal during gestation on parturition in the tammar wallaby (Macropus eugenii). J. Reprod. Fert. 56, 249-254.

Received 25 September 1987 